\title{
Por uma história negra do teatro brasileiro
}

\section{Towards a black Brazilian theater history}

Evani Tavares Lima ${ }^{1}$ 


\section{Resumo}

Este artigo é um recorte de estudos, realizados, a respeito do teatro negro, no doutorado em Artes (UNICAMP, 2010) e em pesquisa pós-doutoral (UFBA, 2011-2015). A reflexão proposta, através deste texto, é a necessidade de contar a história negra no teatro brasileiro. A apresentação e discussão da problemática é realizada, valendose do recurso da escrivivescência (relato de experiência vivida). Em seguida, a título de contribuição a essa história, é apresentado um breve levantamento (histórico-crítico) da presença negra no teatro brasileiro, de seus primórdios, até o início do século vinte. Finaliza esta reflexão, ponderações a respeito do protagonismo negro na autoria desta história.

Palavras-chave: Teatro Negro; teatro brasileiro; história do teatro.

\section{Abstract}

This article is an excerpt of investigations on African Brazilian theatre, carried out during a PhD in Arts at University of Campinas - Brazil (UNICAMP, 2010), and later during a Post-Doctoral research at Federal University of Bahia - Brazil (UFBA, 2011-2015). The reflection proposed in the text encompasses the necessity to discuss how to tell the history of African Brazilian theatre. The text presents and discusses the problem under investigation, by employing the recourse to reports on lived experience, or escrivivência. In order to make further contributions to such a history, a brief historical-critical survey on the presence of Black People in Brazilian theatre is given, from its beginnings to the early Twentieth Century, focusing on the role Black People played in this history.

Keywords: Black Theatre; Brazilian theatre; theatre history.
ISSN: 1414.5731

E-ISSN: 2358.6958 
Meu envolvimento com a temática negra na perspectiva da cena vem desde o início da década de 1990, na graduação em artes cênicas, na Universidade Federal da Bahia. Meu desconhecimento a respeito de atores, dramaturgia e outras referências negras no teatro me conduziram à primeira incursão sobre esse tema do negro e o teatro. O resultado dessa primeira investigação foi a produção de uma, modesta, monografia a respeito do negro no teatro brasileiro ${ }^{2}$. Inicialmente, fui levada a essa pesquisa por um objetivo prático: encontrar personagens para mim, atriz negra, para os exercícios de interpretação teatral, na escola de teatro. Interessante que, ao trocar experiências com colegas a respeito das razões que levaram à escolha desse objeto; a experiência negra na cena, como tema de pesquisa, observo que a motivação é, invariavelmente, a mesma - a necessidade de saber alguma coisa e/ou saber mais a respeito da história negra no teatro brasileiro.

A cada passo dado na direção desse universo de pesquisa, comumente, me deparava com lacunas teóricas, referências não cadastradas e algumas observações, nada animadoras, por parte de alguns professores desprovidos de uma reflexão, mais aprofundada, a respeito das potencialidades da cultura local. Quanto a mim, fazia o caminho de volta para minha história após alguns anos de formação acadêmica, distanciada, de elementos da cultura brasileira. Durante a pesquisa de mestrado, desenvolvi um estudo a respeito das possibilidades da capoeira angola para o treinamento e prática do ator, no teatro ${ }^{3}$. Surpreendentemente, apesar da capoeira ser uma das mais populares e expressivas prática corporal brasileira, encontrei, neste período (2000-2002), apenas, duas referências a seu respeito desse tema no contexto da pesquisa em artes ${ }^{4}$, Armindo Bião e A. Viana (Lima, 2008). Dessa maneira, ao chegar ao doutorado em artes, em 20065, tinha já, alguma, perspectiva do grau de complexidade que envolvia a problemática da presença negra na história do teatro brasileiro ${ }^{6}$. A partir de então, percebi que se apresentava, para mim, um grande universo, cheio de possibilidades e muitas questões a serem respondidas. E que, as lacunas, de toda sorte que ainda ocupam espaço na história negra deste país, não se existiam à toa.

De quando me iniciei na pesquisa a respeito dessa temática, na década de mil novecentos e noventa, até então, devo dizer que já não me sinto tão sozinha. Pois vejo muito mais horizontes do que via no início da caminhada. Questões e descobertas que se apresentam, a cada passo, minhas, dos parceiros e parceiras de caminhada, de nossos interlocutores e debatedores. Penso que esses desafios apresentados por cada nova situação, propiciam a necessária dinâmica do estar em movimento. Nos agrega a novos e velhos pares, enfim, possibilitam o encontro de novas respostas e de outros caminhos. Juntos, separados, e/ou em ressonância, tem-se produzido escritos, promovido encontros e debates, de modo, cada vez mais frequentes, tais

\footnotetext{
${ }^{2}$ Resultou no trabalho de graduação - 0 negro no teatro brasileiro (não publicado).

3 Dissertação defendida em 2002 no PPGAC-UFBA.

4 Exceção se faça ao seu uso espetacular pela dança e por grupos folclóricos.

50 pré-projeto apresentado à seleção do Programa de Pós-Graduação em Artes da UNICAMP, para seleção de 2006, inicialmente, tinha como título: 0 ator no teatro negro.

${ }^{6}$ O doutorado foi defendido em 2010 . O título da tese é Um olhar sobre o teatro
}

negro do Teatro Experimental do negro e do Bando de teatro Olodum, sob orientação da professora livre docente Inaicyra Falcão. 
como: Fóruns de performance negra7, Cenas Pretas $^{8}$, Olanodê ${ }^{9}$, entre outros.

Tendo realizado esse brevíssimo retrospecto, no qual revelo a minha inscrição neste universo, e algumas das razões pelas quais apresento este artigo, início esta discussão problematizando possíveis fatores que concorrem para a incipiência de informações históricas a respeito da presença negra no teatro, no Brasil. Então, faço um relato de uma possível trajetória dessa presença. Para em seguida, realizar algumas ponderações a respeito do caráter e qualidade dessa presença. E por fim, tento explicitar as razões que levam à necessidade de se contar essa história negra do teatro num lugar de autoria. Desse modo, espero poder trazer alguma contribuição às reflexões a respeito dessa temática

Pouco se tem pesquisado e discutido a respeito da experiência negra nas artes cênicas brasileiras. As possibilidades de contribuição do manancial da cultura negra para o teatro, e outras práticas cênicas cena, ainda não foram, suficientemente, analisadas, no contexto das pesquisas artísticas e acadêmicas. E mesmo, discussões e proposições, que vem sendo realizadas por educadores, artistas e investigadores, interessados nessa temática, seja nas artes cênicas ou em áreas afins, encontram dificuldade para fruição.

Em minha perspectiva, tanto a incipiência de estudos, aprofundados, em torno de referências técnicas e simbólicas da cultura negra, bem como a existência, à margem, das proposições, estudos e eventos que envolvem essa temática, em sua espetacularidade, na cena, infelizmente, estão relacionadas, a concepções racistas que, apesar de todas as lutas e avanços, contra elas, ainda, se revelam em muitas esferas da sociedade brasileira ${ }^{10}$. Concepções essas, que serviram, por exemplo, para legitimar as colonizações (invasões) de territórios africanos, sequestros e escravizações de negros e negras, por negociantes europeus. Como justificativa para seus atos criminosos contra outros seres humanos, os colonizadores brancos, europeus, se auto elegeram o modelo de perfeição de beleza, virtude, inteligência, mais que isso, como os verdadeiros seres humanos sob a face da terra. E com essa convicção, subjugaram, destituíram, os outros, os diferentes, de sua humanidade.

Ecos dessas concepções racistas fazem com que, ainda hoje, apesar de todas as lutas e contribuições a este país, a população negra, tenha que brigar por uma cidadania, de fato, reclamando por: direito a uma vida em igualdade de acesso à educação, saúde, trabalho, habitação, e respeito à dignidade. Ainda precisa reclamar o direito de ter sua cultura e valores respeitados, porque a ignorância, a discriminação, a menos valia e a infâmia, ainda pesam sobre eles. Ou seja, todo esse contexto político-social só traz como resultante o alheamento considerável da história negra deste país. E esse desconhecimento de si (já que a cultura negra é um eixo três bases formativas do Brasil), traz consequências diretas a autoestima e ao espelhamento

7 O Fórum Nacional de Performance Negra é resultado da parceria do Bando de Teatro Olodum ( $\mathrm{Ba})$, com a Companhia dos Comuns (RJ). Teve três edições em Salvador; 2005, 2006 e 2009. Reunião em uma rede cerca de cem grupos de teatro, dança e manifestações espetaculares de norte a sul do país.

8 Produzido pelo Bando de teatro Olodum, A cena tá preta é um festival que congrega oficinas artísticas, leituras de textos inéditos, espetáculos, exibição

de filmes, debates, entre outros, em torno da cena negra. Em 2014, teve sua quinta edição.

${ }^{9}$ Evento promovido pela Cia dos Comuns (RJ), também envolve encontros de artistas convidados, mostras de espetáculos e oficinas, em 2007.

10 Guimarães; Huntley, 2000. 
identitário da nação. Acrescente-se a isso a gama de contribuições, aos mais diversos campos, que esse conhecimento histórico pode trazer.

No que diz respeito, ao universo das práticas da cena, o estudo da experiência negra no teatro brasileiro, para além das questões políticas e/ou históricas que implica, oferece um grande leque de perspectivas de investigação. Citarei, apenas, algumas de uma extensa lista de possibilidades: aspectos da presença do artista negro na história da cena - o ator, autor, performer; a temática negra na dramaturgia - personagens, autores; formas negras nas artes cênicas; o aspecto político e identitário; as proposições estéticas; a pedagogia; sua relação com a tradição e o contemporâneo, entre outras.

Fora o ator negro ou mulato quem sustentara a existência do teatro no Brasil colonial (Mendes, 1993, 158).

Em levantamentos feitos por estudiosos no assunto, como Miriam Garcia Mendes (1982; 1993), é possível verificar os vários usos, e formas, atribuídas ao negro, e seus referenciais, nesse universo. De modo que, se pode examinar o negro no teatro brasileiro a partir das seguintes dimensões: utilização de formas, fundadas em princípios negro-descendentes (como fizeram os jesuítas, por exemplo); participação, seja em manifestações espetaculares populares, seja nos palcos, de modo camuflado (usando maquiagem para esconder a negrura); como tema e argumento dramatúrgico; como autor e/ou colaborador na criação das obras. Neste texto, darei ênfase à qualidade dessa presença. Mas antes, tentarei fazer um pequeno desenho desse percurso que se inicia nos primórdios do teatro no país.

[...] era certo ter havido um teatro negro no Brasil desde a $2^{\mathrm{a}}$ metade do século XVI, quando, no período natalino, os escravos promoviam representações de seus autos profanos: Congada, ou Congo, as Taieiras, o Quicumbre, os Quilombos [...]" (Mendes, 1993, 48).

O teatro no Brasil tem início no século XVI, através da catequese cristã, feita pelos padres jesuítas ${ }^{11}$. Inicialmente os indígenas, e depois os negros escravizados, foram, ao mesmo tempo, público e atores desse teatro. Tendo como objetivo doutrinar os "conquistados" em suas crenças e valores religiosos, os colonizadores portugueses valeram-se das línguas, expressões espetaculares e elementos de representatividade simbólica, dos indígenas e negros, para persuadi-los a se converterem à doutrina católica.

Sem adentrar em maiores julgamentos éticos em relação a essa estratégia jesuítica, já que não é esse o objetivo deste texto, podemos dizer que os jesuítas fizeram nascer um teatro que, no "plano ideal" seria o brasileiro: um teatro que comporta em sua forma e fala as três principais matrizes formadoras do Brasil nação: indígena, branca e negra. Esse "plano ideal", ou seja, essa ideia, primeira, de explorar referen 
ciais das nossas três matrizes raciais, como uma maneira de se realizar um teatro que fale a todos os elementos desse triângulo, ainda está por ser, satisfatoriamente, atingido pelo nosso teatro. O que se pode observar, até então, na história do teatro brasileiro é que os referenciais negros e indígenas, foram tratados, ou com menosprezo, ou através de uma reinterpretação sob uma ótica branco-europeia.

Após essa primeira fase do teatro no Brasil, caracterizada pela representação de autos religiosos e espetáculos populares, começa a se desenvolver uma outra modalidade teatral, mais formalmente organizada, cuja natureza profana já não se compatibilizava com o espaço ritual da igreja. Vale notar que, até pouco mais de meados do século XVII, a prática teatral era vista como uma atividade abjeta e por isso condenada pelos que zelavam pela moral e bons costumes da sociedade, de então ${ }^{12}$. Esse desprestígio, talvez, possa explicar o fato dos palcos, dessa época, terem se transformado, pródiga e majoritariamente, em "coisa de preto". Cacciaglia (1986) é um dos estudiosos a registrar essa singularidade:[...] muitas cias já profissionalizadas possuíam elencos quase que só de negros ou mulatos, escravos ou libertos, que interpretavam personagens brancas com o rosto e as mãos pintadas de branco (Caccialia, 1986, 23-24)13.

Vale ressaltar, ainda, de acordo com este autor, que as produções realizadas por esses artistas, atuavam em grandes circuitos culturais da época: Salvador, Diamantina e Rio de Janeiro, por exemplo. Seus espetáculos eram vigorosos; valendo-se de variáveis aparatos cênicos, do canto e da dança.

Dentre essas companhias, merecem destaque; a do Padre Ventura e a de Manuel Luís. Apelidado por Cacciaglia $(1986,81)$ como o "precursor da ópera brasileira", - mulato Padre Ventura tornou-se popular no Rio de Janeiro (por volta do século XVIII), por montar clássicos como Molière e Voltaire com a magnificência de cenário e figurinos, bem, acabados e luxuosos. O também mulato Manuel Luís, dono de uma das primeiras companhias permanentes da época, trazia um elenco de maioria mulata e, do mesmo modo, chamava a atenção pelos espetáculos envoltos em luxo e beleza. Entre seus espectadores constava, nada menos, que a realeza brasileira. Alguns artistas negros e mulatos (atores, diretores e administradores de companhias), desse período, fizeram sucesso também individualmente. Dentre eles: a atriz, Chica da Silva; os atores Vitoriano, Xisto Bahia, Caetano Lopes dos Santos, Maria Joaquina, José Inácio da Costa (o capacho) e o palhaço Benjamim.

Da segunda metade do século XIX, até as duas primeiras décadas do século $X^{14}$, a presença de artistas negros e negras, no palco, foi diminuindo até se tornar escassa. Dá-se então início a um período em que os dramaturgos, numa tentativa de abrasileiramento do teatro nacional, passam a se orientar pela "contemporaneidade de temas e discussão das questões mais frementes do momento" (Braga, 2003, 2): liberdade ou não para os escravizados e as consequências provocadas pelo regime escravocrata para a família e a sociedade, em geral. Dessa maneira, a figura do negro 
retorna à cena brasileira, desta vez, como personagem e mote das peças. Diga-se de passagem, que essa presença era, quase, obrigatória na maioria dos textos da época. Entretanto, a visão distorcida e desumanizada das figuras trazidas à cena, denuncia logo a triste pintura: o negro sob o olhar branco. A marca da ideologia da brancura que vê tudo que não é seu espelho, como inferior, indigno e destituído de qualquer valor. Edélcio Mostaço, ao analisar a maneira como o teatro brasileiro abordou a problemática negra, é taxativo a esse respeito:

Se enfocou de alguma forma o negro e sua situação social e política, deixou de fazê-lo enquanto ser cultural específico, antropologicamente distinto, consubstanciado dentro de um ethos racial que, para além do folclore, apresenta inúmeras diferenças (Mostaço, 1988, 57).

\section{Negro sob olhar Branco}

A presença do negro na dramaturgia e no teatro brasileiro foi investigada de modo, muito, significativo, por Miriam Mendes, nas obras; A personagem negra no teatro brasileiro (1982) e O negro e o teatro brasileiro - entre 1889 e 1888 (1982). Considero suas obras, referências no assunto, por essa razão, utilizo-as como base para fazer algumas ponderações a respeito da maneira como se deu essa presença negra como mote e inspiração das peças escritas, no auge dos debates sobre a abolição do trabalho escravo negro.

Quando nosso teatro se propôs a colocar o negro como a figura principal do drama, lhe desfigurou e desumanizou. De modo geral, uma ínfima minoria de autores chegou a se desviar do padrão de tratamento dado ao negro em sua dramaturgia. A grande maioria se preocupou em, no máximo, retratar uma única realidade: a do ser condenado à condição de escravizado e desprovido de humanidade e individualidade. O grande uso que se fez dessa temática, num período que antecede a promulgação da escravatura no Brasil (1888) se deu majoritariamente em seu desserviço. Invariavelmente, como registra Mendes (1982), nessas peças, o negro é circunscrito numa área na qual somente lhe é permitido representar o feio, o torpe, o mal, o degradado da sociedade. Segundo a autora, essa atitude seria decorrente de uma estratégia para mascarar e justificar a repressão e a discriminação praticadas contra os indivíduos negros descendentes no país.

Certamente, essa visão limitada dos escritores de teatro, não só restringiu o espaço de atuação dos artistas negros, mas também impingiu a todo povo negro, um estigma de "eterno escravo e subalterno" que perdurou mesmo depois de ter alcançado sua liberdade. A repetição de estereótipos, reforça-os e constrói imaginários que fortalecem ainda mais sua proliferação, e foi isso que se deu com muitas das distorções criadas por esses autores brancos, para representar o negro. De fato, ainda hoje, sem nenhum esforço, podemos sentir os ecos desse mal. Basta que atentemos, um pouco, para as obras produzidas e/ou endossadas por alguns de escritores, tele dramaturgos, produtores e espectadores. Creio que não haverá dificuldade em 
encontrar alguns velhos estereótipos associados ao povo negro: o "bom escravo", a "mucama", o "preto velho", a "tia Anastácia", a "mulata faceira", o "moleque irresponsável".

Pode-se analisar boa parte das figuras negras que surgiram na dramaturgia do teatro brasileiro, por volta do final do século XIX, a partir de três principais variantes: 0 escravo fiel, o negro ruim, e o bom negro. Em torno dessas tipificações, outras tantas, variações foram sendo criadas. Dessa maneira, por exemplo, o escravo fiel, tal qual um cão, é leal ao seu senhor mesmo em seu prejuízo e aos seus; o negro ruim, ou negro revoltado ${ }^{15}$, é aquele que combate e denuncia a situação de opressão vivida pelo negro. Com este tipo deve-se ter cuidado, pois ele pode insuflar outros à revolução. Em oposição ao negro perigoso, há o bom negro, cuja bondade não é mérito dele, mas de seu senhor, o branco. O bom, nesse caso, é aquele que afirma a branquitude e seus elementos simbólicos, rechaçando o negro que era (Mendes, 1982).

Mendes (1982), apresenta uma grande relação de autores que desenharam o negro, enquanto personagem, na literatura brasileira ${ }^{16}$. Não me proponho a passá-los em revista, pois o mesmo já foi feito, magistralmente, por ela. Citarei, aqui, apenas alguns exemplos que, podem ser mais ilustrativos para esta discussão. Desse modo, é importante salientar que o relevo dado a esses autores, neste momento, é muito mais, pelo fato de terem trazido em seus textos personagens negras do que exatamente pela forma como o fizeram. Já que grande parte das obras produzidas por eles espelha o olhar e a compreensão de sua época sobre o negro. Assim, conscientes ou não da ideologia que ajudaram a legitimar, acabaram por validar em suas peças a maioria dos estereótipos difundidos pela sua sociedade.

De acordo com o levantamento realizado pela autora (1982), a grande maioria, das personagens, aparece nos enredos apenas para compor o cenário, a título de ilustração da realidade da época. Dentre algumas das funções usualmente atribuídas a elas está a de compor o ambiente, de torna-lo mais crível, tal qual uma paisagem. Até mesmo Martins Pena ${ }^{17}$, um dos mais importantes dramaturgos do século XIX, notabilizado por suas comédias, que retratam o cotidiano da época, ao incorporar a temática negra, utiliza personagens negras como elemento de composição do local. $\mathrm{E}$, mesmo quando as coloca como peça importante da trama, como acontece em duas de suas obras (O Cigano - 1845; Os Dous ou o inglês maquinista - 1842), estão inseridas nesse lugar comum, "paisagem"; nem tão pouco, escapam aos estereótipos.

De acordo com Mendes (1982), José de Alencar ${ }^{18}$, inova ao trazer, pela primeira vez, em dois de seus textos, O Demônio Familiar (1857) e A Mãe (1860), "personagens negras de grande categoria da dramaturgia nacional". Os personagens Pedro (O Demônio Familiar) e Joana (A Mãe), pela condição de escravizados, servem como

\footnotetext{
15 O Negro Revoltado (1982) é, talvez, não por acaso, o título do livro publicado pelo professor Abdias do Nascimento, pela Nova Fronteira. O livro reúne uma série de conferências proferidas pelo autor.

16 Luís Carlos Martins Pena, Joaquim Manoel de Macedo, José Martiniano de Alencar, Agrário de Meneses, Carlos Antonio Cordeiro, Francisco Pinheiro Guimarães, Paulo Eiró, Maria Ribeiro, Antonio de Castro Alves, Cândido Barata Ribeiro e Ubaldino Pompeu do Amaral, J.P. da Costa Lima, França Júnior, Artur Azevedo e Visconde de Taunay.
}

\footnotetext{
17 Luis Carlos Martins Pena (1815-1848), considerado o "Molière" brasileiro, é autor de 28 textos, dos quais 23 são comédias. Entre as peças, o personagem negro aparece em: Juiz de Paz na roça, Um sertanejo na corte, A noite de São João, $O$ cigano, A família e A festa na roça, Os dous ou o inglês maquinista. 18 José Martiniano de Alencar (1830/1877), deputado e ministro da justiça, jornalista, escritor, advogado e crítico. Escreveu os romances $O$ guarani e Iracema e as peças: $O$ demônio familiar, A mãe, A expiação, entre outras (Caccialia, 1986, 199).
} 
motes para o autor criar dois textos totalmente inseridos no contexto social da época (Mendes, 1982). Dois outros autores, Paulo Eiró ${ }^{19}$ e França Jr. ${ }^{20}$, também merecem realce neste painel por terem criado dois tipos que se tornaram bastante presentes em nossa dramaturgia: o mulato e a mulata. Tais tipos se tornariam símbolo de brasilidade - da união das três raças - e a exaltação ao mestiço. Compuseram figuras que serão bastante visitadas por nossos dramaturgos; o mulato e a mulata. Que, ao contrário do negro retinto, terá o privilégio de ser alçado à condição de personagem (Mendes, 1982, 188).

É na peça Sangue Limpo (1861) que Paulo Eiró introduz a figura do mulato: o homem livre que sofre retaliações por sua ascendência negra, sendo a cor de sua pele um impedimento para sua ascensão social. França Jr., por sua vez, trará em sua comédia Direito por Linhas Tortas (1870), a variante feminina desta figura, aquela que se tornará um tipo de "paixão nacional": a mulata. Bela, sensual e sedutora, a mulata é um misto de candura e animalidade.

Vale ressaltar, dentro desse panorama, exceções feitas, pela autora, a Artur Azevedo21, Agrário de Menezes ${ }^{22}$ e Castro Alves ${ }^{23}$. Segundo ela, é Arthur Azevedo quem pioneiramente apresenta uma personagem negra fora do modelo usualmente convencionado. Em O Escravocrata (1882), o velho escravo Lourenço é "altivo, decidido, capaz de agir deliberadamente, como um homem..." (Mendes, 1982, 165). Nesse texto de Azevedo ainda aparece uma segunda personagem negra: Gustavo, mulato que criado como um senhorzinho descobre, na verdade, ser filho de um escravo. Agrário de Menezes e Castro Alves também inovaram ao traçar a personagem negra como humana e passível de ser acometida pela tragédia. Agrário de Menezes escreve a estória de Calabar (1856), um herói mestiço que se vê atormentado por causa de sua origem negra e pobre. E, por sua vez, Castro Alves, em Gonzaga ou A revolução de Minas (1867), apresenta a personagem mulata, Carlota, uma personagem dramática, bem delineada e com atuação na trama.

Considerei pertinente trazer um recorte do trabalho realizado por Miriam Mendes, justamente pelo possibilita em termos de dimensionamento histórico, do tratamento dado a personagem negra, do nascimento e persistência do uso de alguns estereótipos, associados ao povo negro, ainda hoje, recorrentes na dramaturgia e teledramaturgia, no Brasil.

\section{Negros, negras e companhias - e um "Teatro Ligeiro"}

O teatro do século XX, no Brasil, é marcado por uma grande efervescência dentro e

\footnotetext{
19 Paulo Eiró (1836-1871) escreveu poesia, história, prosa, folclore e teatro. Entre suas peças estão: Sangue limpo, 0 traficante de escravos e Pedra filosofal.

20 França Jr, (1838-1890) formado em direito, foi promotor, escritor e jornalista. Escreveu Direito por Linhas tortas e Como se fazia um deputado.

${ }^{21}$ Artur Nabantino Gonçalves de Azevedo (1855-1908) nasceu no Maranhão; pregava um teatro nacionalista, e foi um dos que defenderam a fundação do teatro Municipal do Rio de Janeiro. Escreveu muitas peças, entre elas: Amor
}

por Anexins, Liberato, O Escravocrata e O Dote.

22 Agrário de Meneses (1834/1863) nasceu na Bahia; era advogado, jornalista, poeta, deputado e escritor. Escreveu, entre outras obras: Matilde, Os Miseráveis, Bartholomeu de Gusmão e Uma festa no Bonfim.

23 Antonio de Castro Alves (1847/1871) era baiano e ficou famoso como o "poeta dos escravos". Escreveu: Gonzaga ou a revolução de Minas (1867) e D. Juan ou A prole dos Saturnos (1868/1869). 
fora dos palcos. Há todo um movimento social que transforma a todos. O número de espectadores aumenta e se diversifica; agora, também o povo tem acesso ao teatro. Constantes debates em torno de uma maior autenticidade do teatro nacional se tornam comuns, nessa época, o que, posteriormente, abrirá caminho para sua necessária renovação. Mas, antes, nas primeiras décadas, mudanças socioculturais transformam nossas metrópoles e levam seus reflexos para os palcos que começam a ser tomados por um estilo ligeiro de fazer teatro (Braga, 2003; Gomes, 2003).

Nesse período, o cinema, inaugurando seus primeiros passos no país, põenos em contato o mundo maravilhoso da cultura de massa ${ }^{24}$. Salas e mais salas de espetáculos, nos grandes centros, passam a exibir filmes, em sua maioria filmes norte-americanos. Essa presença do cinema acaba por atingir sobremaneira o teatro. Os espectadores, por exemplo, passam a frequentar as salas de cinema, deixando para traz plateias vazias. Muito seguramente não por acaso, nesse período, um estilo de teatro influenciado pelos musicais americanos (assistidos nos cinemas) e por algumas formas de comédias, particularmente oriundas do vaudeville 25 francês, começa a se popularizar e novamente a encher as salas de espetáculos.

Nessa época, o teatro de revista que chegou ao Brasil, no final do século XIX, começa, aos poucos, a ocupar espaço. Esse teatro, possui um formato multifacetado, num misto de teatro e música, que emprega a dança, a paródia, a caricatura, a comicidade e a pilhéria como recursos. Seus espetáculos são divididos em quadros (não necessariamente interligados), ao invés de cenas. Trata de temas correntes e se utiliza de linguagem e tramas fáceis. Além de falas de duplo sentido e utilização de músicas retiradas do cancioneiro popular (Braga, 2003; Gomes, 2003).

É através desse estilo popular, do teatro de revista, que a presença negra se fará, novamente, notável. De acordo com Gomes (2003), a presença de artistas de ascendência negra em companhias de teatro de revista da época era bastante comum: havia belas e insinuantes dançarinas (as famosas "black girls"), que eram um atrativo à parte para a plateia masculina. Aliás, a dança, em suas muitas variantes, era também um campo fértil nos espetáculos teatro de revista, "danças que se caracterizavam pela proximidade corporal ou a presença significativa de produtos culturais associados aos descendentes de africanos" (Gomes, 2003, 11), como o maxixe e o samba, por exemplo. Entre os artistas desse teatro, alguns já célebres, estavam a dançarina de maxixe, Plácida dos Santos; a cantora Araci Cortes; as atrizes Ascendina dos Santos, Rosa Negra, e Jaci Aymoré; os músicos Bonfilio de Oliveira, Sebastião Quirino, Pixinguinha e Eduardo Neves (também ator); e o ator Benjamim de Oliveira26. No âmbito da dramaturgia, ainda de acordo com Gomes (2003), peças de teatro ligeiro, sem uma "mulata" ou "baiana", era uma coisa inusitada.

Segundo Nepomuceno (2006), durante o período que até por volta de 1950, as revistas negras foram bastante atuantes, dando espaço para artistas negros em todas ${ }^{24}$ Além disso, por conta de toda a circulação de companhias, no início do
século XX, em diferentes praças, tanto na Europa como na América Latina,
atua como facilitadora de intercâmbio entre diferentes artistas da diáspora, o
que possibilita que uma certa ressonância entre tudo do que se fazia lá, aqui.
(Nepomuceno, 2006; Gomes, 2003).
25 "Ou vaux de vire - espetáculo de canções, acrobacias e monólogos. Popularmente, tornou-se sinônimo de teatro leve, tramas simples e feito para divertir" (Pavis, 2005, 427).

${ }^{26}$ Até hoje é considerado pela maioria dos estudiosos o maior palhaço brasileiro. 
esferas: dançarinos, músicos, cantores, comediantes, produtores, entre outros. Dentre essas companhias de destaque, três são pertinentes: Companhia Negra de Revistas (1926), Companhia Bataclan Negra (1927), Companhia Mulata Brasileira (1930)27. Destas, a mais célebre é a Companhia Negra de Revistas, criada no Rio de Janeiro, em 1926, pelo músico De Chocolat (João Candido Ferreira) e pelo empresário Jayme Silva. Essa companhia trazia, em seu elenco, músicos prodigiosos como Bonfílio de Oliveira, Sebastião Quirino e Pixinguinha. Em suas mais de quatrocentas apresentações, excursionou pelo Rio de Janeiro, São Paulo, Minas Gerais, Bahia, Pernambuco e Rio Grande do Sul (Nepomuceno, 2006).

Na opinião de Nepomucemo (2006), a Companhia Negra de Revistas, entre outras, ampliou o "espaço para a discussão de temas caros a [...] uma plateia diversificada racial, social e culturalmente" (Nepomuceno, 2006, 26). Ou seja, dentro de uma atmosfera lúdica e através da comicidade, o grupo consegue trazer ao palco a discussão e a reflexão sobre "relacionamentos étnico-culturais - e de partilhas de experiências negras do viver urbano" (Nepomuceno, 2006, 14). Por essa razão, a autora considera que foram as revistas negras, e não o Teatro Experimental do Negro, as pioneiras a trazerem a questão negra para os palcos brasileiros.

De acordo com Gomes (2003), a popularização de personagens e artistas negros durante esse período era consequência de uma "moda", sucesso em França, de trazer em seus elencos integrantes negros. Até onde foi possível verificar, esse largo espaço ocupado pelos artistas negros não representou exatamente uma mudança de mentalidade na relação entre os detentores das regras de produção cultural e os artistas negros. Ao menos no ponto de vista de lhes render benefícios, ou mesmo diminuir a associação da imagem do negro a valores diminutivos. Ou seja, atendia muito mais a uma estratégia comercial do que a qualquer avanço, no que diz respeito à reedificação do negro e sua cultura nos palcos. A mulata, por exemplo, servia para alimentar a ideia da bem-sucedida mestiçagem brasileira, e, ao mesmo tempo, era apresentada como uma "produção" tipicamente brasileira, cujos atributos eram a sensualidade latente e a beleza animal.

Assim, a maneira como esse teatro se apropriou dos referenciais negros pode ser comparada a uma faca de dois gumes: popularizou e fortaleceu estereótipos (malandro = sambista e avesso ao trabalho; mulata $=$ boa de rebolado e produto de exportação, entre outros) e, abriu espaço para atuação do artista negro (Rosa, 2007). E essa, vejo como uma das grandes encruzilhadas no caminho da história negra no teatro brasileiro. Como escapar aos estereótipos, como combatê-los, como demovê -los? O fato é que se faz necessário estar atento para repetir velhos erros que insistem em retornar à primeira distração.

Até que os leões contem a sua história, as histórias de caça sempre glorificarão o caçador. ${ }^{28}$

\footnotetext{
${ }^{27}$ As três companhias tiveram como idealizador o músico, compositor, diretor, empresário e escritor João Candido Ferreira, o De Chocolat (Nepomuceno, 2006).
}

28 Provérbio africano de autoria desconhecida. 
Como não repetir os mesmos erros ao reescrever a história negra? Assumindo o lugar da caça, prestando muita atenção aos rastros deixados por concepções unilaterais, que não falam com sua própria língua, mas com a de outrem, pseudo universal, com a intenção de "retratar a realidade". Daí a importância de ocupar o lugar de escrever a própria história. Quando assino, nomino, faço existir, dou voz e corpo. Afirmo o Eu Sou, Eu Penso, Eu Faço. Frente ao contexto sócio político de violação, exclusão e invisibilidade da história negra, a autoria se torna um instrumento importante, pois, ela fará o existir. E é somente a partir da existência que tudo se dá. Sem se fazer existir, penso que não seja possível se conhecer e se reinventar. Enfim, sem invocar a responsabilidade dessa autoria fica-se à mercê de uma história torta que só vem refletir o que já está posto.

Dessa maneira, gostaria de assinalar que esse chamado por uma história negra do teatro brasileiro, é também uma provocação à autoria: qualidade ou condição de autor. Significa, no sentido jurídico, dado pelo Dicionário Aurélio, "invocar a responsabilidade de algo" ... de escrever o que não tem sido dito, de retratar o que tem estado à margem.

Muito de nossa história ainda passa de boca em boca, ou está nas entrelinhas dos registros oficiais, ainda não chegaram às vitrines, às resenhas dos jornais e revistas, e muito menos às bibliotecas escolares e universitárias. Diante dessa situação, uma tarefa muito comum a quem se envereda por esse universo do teatro negro é de ser escavador/a de sua própria história. Seja de par, luneta, ou com palavras em punho trabalhemos para tornar visível aquilo que não se pode calar!

\section{Referências}

ARAÚJO, Joel Zito. A negação do Brasil: o negro na telenovela brasileira. São Paulo: Senac/SP, 2000.

BRAGA, C. Em busca da brasilidade: teatro brasileiro na primeira república. São Paulo: Perspectiva; Belo Horizonte: FAPEMIG; Brasília: CNPQ: 2003, série Estudos,194.

BROOKS, D. Black theatre and performance studies: seminal critical essays and articles. PALMER, C (ed.). Cultural Life. Michigan State University Press: 2005/2007.

CACCIAGLIA. M. Pequena História do Teatro no Brasil (quatro séculos de teatro no Brasil). Apresentação de Sábato Magaldi. Tradução de Carla de Queiroz. São Paulo: T. A. Queiroz: Ed. Da Universidade de São Paulo, 1986 (Biblioteca de Letras e Ciências Humanas; série 2; Textos; v. 4).

GOMES, T. "Como eles se divertem" (e se entendem): teatro de revista, cultura de massas e identidades sociais no Rio de Janeiro dos anos de 1920. 2003, 422 pp. Tese (Doutorado em História), Universidade Estadual de Campinas, Campinas, 2003.

MARTINS, L. A. Cena em Sombras. São Paulo: Perspectiva, 1995. 
MENDES, M. G. A Personagem Negra no Teatro Brasileiro. São Paulo, Ática, 1982.

MENDES, M. G. O Negro e o Teatro Brasileiro (entre 1889 e 1888). São Paulo: Hucitec; Rio de Janeiro: Instituto Brasileiro de Arte e Cultura; Brasília: Fundação Cultural Palmares, 1993.

MOSTAÇO, E. O legado de Set. In MÜLLER, R. G. (Organizador). Revista Dionysos. Especial: Teatro Experimental do Negro. Organização: Ricardo Gaspar Muller. Rio de Janeiro: FUNDACEN, 1988.

NASCIMENTO, A. A Energia do Inconformismo. In MÜLLER, R. G. (Organizador). Revista Dionysos. Especial: Teatro Experimental do Negro. Organização: Ricardo Gaspar Muller. Rio de Janeiro: FUNDACEN, 1988.

NASCIMENTO, A. Teatro experimental do negro: trajetória e reflexões. Estudos Avançados. vol.18 no.50. São Paulo Jan./Apr. 2004, p. 16.

NASCIMENTO, A., SEMOG, E. Abdias Nascimento: o Griot e as Muralhas. Rio de Janeiro: Pallas, 2006.

NEPOMUCEMO, N. Testemunhos de Poéticas Negras: De Chocolat e a Cia Negra de Revistas no Rio de Janeiro (1926 1927). 2006. 167pp. Dissertação (Mestrado em História) Pontifícia Universidade Católica de São Paulo, São Paulo, 2006.

PAVIS, P. Dicionário de teatro. Tradução: J. Guinsburg e Maria Lúcia Pereira (direção). São Paulo: Perspectiva, 2005.

ROSA, D. R. A. Teatro Experimental do Negro: estratégia e ação. 2007, 174pp. Dissertação (Mestrado em Sociologia). - IFCH, Universidade Estadual de Campinas, Campinas, 2007.

Recebido em: 20/01/2015 Aprovado em: 02/07/2015 